\title{
Assessment of Exemplary Leadership Practices in Different Government Offices in Nekemte Town, Oromia Regional State, Ethiopia
}

\author{
Dereje Negesa Hordofa \\ (BA in Management, MBA in Business Administration) \\ (Head and Lecturer in Department of Management, Wollega University)
}

\begin{abstract}
The study was aimed at to assess an exemplary leadership practices in different government Offices in Nekemte town, Oromia Regional State, Ethiopia in light of five kouzes and posners leadership practices model and provide constructive suggestions. The study employed descriptive approach. Primary data was obtained from 120 position holders/leaders/ of different government Offices in Nekemte town those who participated on offered leadership and capacity building training for two days (May 3-4, 2017) which was organized by training and development center in collaboration with corporate communication directorate office of Wollega University to acquire firsthand information of the situation under the study and draw valid conclusion. As a result of data analysis and the findings of the study, position holders/leaders/ of different government Offices in Nekemte town moderately Model the Way, Inspire a Shared Vision, Challenge the Process, Enable Others to Act, and Encourage the Heart. The researcher would like to offer recommendations for Oromia Regional State Bureau to plan and invest resources in transformational leadership development of all managers and leadership team members in zonal levels of the region which affects productivity in all angles. Lastly, five models of transformational leadership practices will be suggested for all position holders/leaders/ of different government Offices to implement and become productive leader for Organizational success and good governance.
\end{abstract}

Keywords: Exemplary leadership practices, government Offices, Nekemte town, Oromia Regional State, Ethiopia DOI: $10.7176 / \mathrm{EJBM} / 11-25-03$

Publication date:September $30^{\text {th }} 2019$

\section{Introduction}

Leadership is a critical component of good public governance, which is a major theme for current OECD work. Governance can be briefly described as the way in which the underlying values of a nation (usually articulated in some way in its Constitution) are "institutionalized". This has formal aspects such as separated powers, checks and balances, means of transferring power, transparency, and accountability.

However, for these values to be actualized, they must guide the actions of public officials throughout the system. They must be imbedded in culture. In this regard "leadership" is the flesh on the bones of the Constitution. It is at the heart of good governance (OECD, 2011).

Leadership is an important and crucial variable that leads to enhanced management capacity, as well as organizational performance. A leadership focus also plays an integrating role among various Human Resource Management components including recruitment and selection, training and development, performance management, public service ethics, and succession planning.

Ramnarayan, S. \& Kumar, K. (2004) noted that understanding the way to improve performance in public sector is very important to assure the better productivity of it. Therefore, many countries have reformed its public sector to meet the public demand of more transparent and accountable to government. In addition, the evolution or new technology has put the government to devise the integrity value of public sector with strong command in leadership to steer the efficiency without abandoning the value of good governance. In such situation, exemplary leadership practices can help to achieve the quality and positive outcomes.

The Five Practices framework is consistent with transformational leadership models (Bass, B.M. 2008, Yukl, G.A. 2012). Bass and Riggio(2006) note that the LPI has been much more widely used by practitioners than it has been applied in published empirical research. Kouzes and Posner $(2012,1988)$ note that the original purpose of the LPI was for leadership development, helping individuals become more effective leaders through selfassessment and feedback from constituents, rather than for the empirical or scholarly study of leaders.

Two recent research reports offer strong empirical support for the impact of The Five Practices of Exemplary Leadership model (Kouzes \& Posner, 2007). Together they show that the more we can get leaders in our organizations, at all levels, to Model the Way, Inspire a Shared Vision, Challenge the Process, Enable Others to Act, and Encourage the Heart, the better off will companies and their constituents be.

In a survey involving 94 companies, Richard Roi (2006) asked executives to rate their company's senior leadership on The Five Practices of Exemplary Leadership by completing the Leadership Practices Inventory (LPI). Then he analyzed the company's long-term financial performance (over a 10-year period; 1996 - 2005) using net 
income and stock price growth. The relationship between transformational leadership practices (combining all five leadership practices into a single measure) and company financial performance was dramatic

This study attempts to explore an exemplary leadership practices by holders/leaders/ of different government Offices in Nekemte town, Oromia, Ethiopia. The findings of the study will help different government organizations and understand their level of practices of exemplary leadership.

\section{Statement of the problem}

Ethiopia has facing many obstacles and challenges. Consequently, the public sectors have been subjected to criticisms for inefficiency, lack of flexibility, ineffective accountability and poor performance for a long period of time. Poor service delivery had reflected gaps in accountability, inequalities in policy planning, and inadequate coordination across public agencies, especially at zonal, and woreda levels have led to discontent with government services.

A look into local studies in the area of leadership indicates that no research goings-on the Kouzes and Posners model which is well recognized in enhancing organizational success to examine exemplary leadership practices. Hence, there is no evidence reported that identifies the degree to which position holders/leaders/ of different government Offices in Nekemte town practice Kouzes and Posner's Transformational Leadership Model using five exemplary Leadership Practices.

The society complain that the management team was mostly observed trying to maintain status quo instead of managing change and leading the organization towards adapting to the new changing environment and facilitate implementation by creating conducive atmosphere required to ensure social responsibilities.

To this end, the study attempted to answer the following basic research question:

E To what extent do position holders/leaders/ of different government Offices in Nekemte town exercise the five Kouzes and Posner's exemplary leadership practices to change and transform their institutions/organizations?

E Which of the five Kouzes and Posner's exemplary leadership practices are the most or least exercised by the leadership teams of the town?

\section{Objectives of the Study}

The study was aimed at investigating exemplary leadership practices of holders/leaders/ of different government Offices in Nekemte town in light of five kouzes and posners exemplary leadership practices model and provide constructive suggestions.

The specific objectives of the study were to:

E Examine the extent to which holders/leaders/ of different government Offices in Nekemte town exercises the five Kouzes and Posner's exemplary leadership practices for effective implementation of change; and social responsibilities.

- Identify the most and the least exercised Kouzes and Posner's Exemplary leadership practices by holders/leaders/ of different government Offices in Nekemte town;

- To offer suggestions for all concerned individuals, organization / Institutions how to improve exemplary leadership practices so as to be productive.

\section{Literature review}

The Leadership Practices Inventory (LPI) is conceptually based on the transformational leadership model of Kouzes and Posner (Kouzes, J.M.; Posner, B.Z, 2012).

This model emerged from their analysis of thousands of case studies of people's personal-best leadership experiences; the times when these individuals accomplished something extraordinary (Northouse, P.G. 2016, Kouzes, J.M.; Posner, B.Z.1988, 1990). The model postulates that there are five exemplary leadership practices: Model the Way, Inspire a Shared Vision, Challenge the Process, Enable Others to Act, and Encourage the Heart. These practices provide the groundwork for organizational success, by recommending what behaviors and actions people need to do to become effective leaders (Northouse, P.G. 2016). The five leadership practices are described in these ways:

Model the Way

To model the behavior they expect of others effectively, leaders must first be clear about guiding principles. Leaders establish principles concerning the way people (constituents, peers, colleagues, and customers alike) should be treated and the way goals should be pursued. They create standards of excellence and set an example for others to follow (Kouzes, J.M.; Posner, B.Z, 2012).

Inspire a Shared Vision

Leaders passionately believe that they can make a difference. They envision the future, creating an ideal and unique image of what the organization can become. They breathe life into their visions and get people to see exciting possibilities beyond the horizon. They listen to the hopes and aspirations of others, so that by incorporating these, 
people can enlist in a shared dream about the future (Kouzes, J.M.; Posner, B.Z, 2012).

\section{Challenge the Process}

Leaders aspire to improve upon the status quo by searching for opportunities to grow and innovate, many of which are outside of their customary boundaries. They experiment and take risks, and gain momentum through achieving small wins. They look upon setbacks as learning opportunities, for both themselves and their constituents (Kouzes, J.M.; Posner, B.Z, 2012).

Enable Others to Act

Leaders foster collaboration, build trust, and create spirited teams. They actively involve others and understand that mutual respect is what sustains extraordinary efforts; they strive to create an atmosphere of trust and human dignity. They strengthen others, making each person feel capable and powerful (Kouzes, J.M.; Posner, B.Z, 2012). Encourage the Heart

Leaders make people feel like winners. They keep hope and determination alive by appreciating contributions that individuals make. They recognize that everyone's contributions are valued, creating a sense of community by celebrating the team's victories. They establish high expectations and standards, holding people accountable to them by ensuring that rewards and performance are linked (Kouzes, J.M.; Posner, B.Z, 2012).

\section{Conceptual framework}

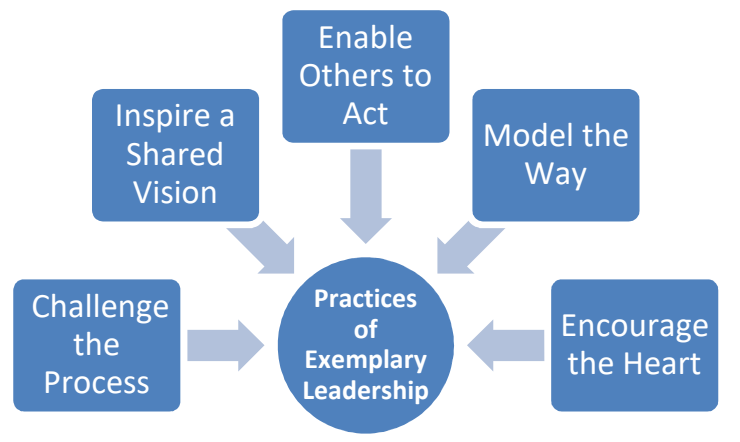

Figure 1: Fundamental Practices of Exemplary Leadership

\section{Research Design and Methodology}

The study employed descriptive approach. This design was selected as it was suitable to sufficiently explain the current practices of position holders/leaders/ of different government Offices in Nekemte town to draw valid general conclusion.

\section{Source of Data and Population of the Study}

Primary data was obtained from position holders/leaders/ of different government Offices in Nekemte town to acquire first-hand information of the situation under the study and draw valid conclusion.

The population of the study was 120 position holders/leaders/ of different government Offices in Nekemte town those who participated on offered leadership and capacity building training for two days (May 3-4, 2017) which was organized by training and development center in collaboration with corporate communication directorate office of Wollega University.

\section{Data Collection instruments}

The study used quantitative data to identify and analyze the status of exemplary leadership practices of position holders/leaders/ of different government Offices in Nekemte town, compare its existing condition with the reviewed research findings and to draw a general conclusion. The quantitative data were gathered through closeended questionnaire. Questionnaire was used as a main tool for data collection. The questionnaire was used to gather data from 120 sample position holders/leaders/ of different government Offices in Nekemte town who were participated on training. The return rate was $120(100 \%)$.

Leadership Practice Inventory (LPI) observer questionnaire based on Kouzes and Posner's Transformational Leadership Model was used for this purpose. There are two versions of LPI (Self and Observer). LPI observer questionnaire was used and LPI self was excluded to minimize potential leaders' self-report bias.

The Kouzes and Posner's LPI Observer questionnaire was structured closed ended questionnaire with 5 point Likert scale of thirty items leadership practice. Therefore, it was appropriate not only for the researcher to obtain reliable response from the respondents but also for the respondents to choose one option from the given scales that best align with their views.

The dimension "Modeling the Way" is evaluated by the items 1, 6, 11, 16, 21 and 26. The second dimension "Inspiring a Shared Vision" is evaluated by the items 2, 7, 12, 17, 22 and 27. The items 3, 8, 13, 18, 23 and 28 evaluate the third dimension "Challenging the Process". The items 4, 9, 14, 19, 24 and 29 evaluate the fourth 
dimension "Enabling Others to Act". The fifth dimension "Encouraging the Heart" is evaluated by the items 5, 10, $15,20,25$ and 30 of the instrument.

In the instrument, the participants read the statements of the instrument and provide their response on a five point Likert scale $(1=$ rarely, $2=$ once in a while, $3=$ sometimes, $4=$ often, and $5=$ very frequently).

Data Analysis

The quantitative data collected through close ended questionnaires were tallied and tabulated. Mean and standard deviation were used to measure the degree to which position holders/leaders/ of different government Offices practice Kouzes and Posner's

Transformational Leadership Model as measured by Leadership Practices Inventory (LPI). The quantitative data were analyzed using the Statistical SPSS 24. To assure participant confidentiality, results were presented only in aggregate form.

The data were analyzed through the following procedures.

Numerical descriptive approach was used to compute the means and standard deviations to convey the average and to summarize the data of the five variables. Accordingly, the finding was analyzed as $(\mathrm{X}<2.49=10 \mathrm{w}$ practice, $\mathrm{X}>2.5<3.49=$ Moderate, $\mathrm{X}>3.5<4.49=$ Good Practice, $>4.5<4.75=$ Very Good Practice, $4.75-5=$ Excellent. Where, Mean (X).

\section{Result and discussion: Data Presentation and Analysis Introduction}

This part of the article presents the results of the data gathered from position holders/leaders/ of different government Offices in Nekemte town by using questionnaire. This article deals with one of the basic research questions: To what extent do position holders/leaders/ of different government Offices in Nekemte town exercise the five Kouzes and Posner's exemplary leadership practices to change and transform their institutions/organizations? And which of the five Kouzes and Posner's exemplary leadership practices are the most or least exercised by the leadership teams of the town?

Based on the research design of the main research the questionnaire was distributed to 120 respondents and $120(100 \%)$ were successfully responded were organized and interpreted in view of the objective of the study and research questions.

Table1: Gender of respondents (leaders)

\begin{tabular}{|l|r|l|l|}
\hline & & Frequency & Valid Percent \\
\hline \multirow{3}{*}{ Gender } & 1 & 75 & 62.5 \\
\cline { 2 - 4 } & 2 & 45 & 37.5 \\
\hline & Total & 120 & 100.0 \\
\hline
\end{tabular}

As shown in the first part of the above table 1, out of the total position holders/leaders/ of different government Offices in Nekemte town, male accounts for $62.5 \%$ (75) and $37.5 \%$ (45) were females.

Table2: Analysis of leaders challenge the process

\begin{tabular}{llcc}
\hline & Leadership Behavior & Mean & Std. Deviation \\
\hline $\mathbf{1}$ & I look for opportunities that will test my skills and abilities. & 3.4 & 1.49 \\
$\mathbf{2}$ & I stay up to date on new developments in my field or in my organization. & 2.89 & 1.27 \\
$\mathbf{3}$ & I challenge the way people do things at work. & 2.74 & 1.20 \\
$\mathbf{4}$ & I look for innovative ways the team can improve what is done for the organization & 2.45 & 1.07 \\
$\mathbf{5}$ & I ask 'what can we learn' when things do not go as expected & 2.9 & 1.27 \\
$\mathbf{6}$ & I take risks with the way things are done even if there is a risk of failure & 3.2 & 1.40 \\
& Grand Mean & $\mathbf{2 . 9 3}$ & \\
\hline
\end{tabular}

When the six variables under the leadership practice i.e. "Challenging the Process" were ranked from the highest to the lowest mean score (Table 2), variable number 1 i.e. looking for opportunities that will test my skills and abilities was rated relatively the highest mean 3.40 where as the variable ranked the lowest was looking for innovative ways the team can improve what is done for the organization with mean score 2.45 . As can be seen from the table, the mean scores for the five variables related to "Challenging the Process" were between 2.5 and 3.49. Thus, one could conclude that the position holders/leaders/ of different government Offices in Nekemte town moderately Challenge the Process. It is also interesting to note that the mean for variable 4 was less than 2.5 which indicated that the position holders/leaders/ of different government Offices in Nekemte town was below moderate which implies they are reluctant to innovativeness. The aggregate mean 2.93 shows that the extent to which leaders challenges the process is moderate. 
Table 3: Extent to which the Leaders Inspire a Shared Vision

\begin{tabular}{llcc}
\hline \multicolumn{2}{l}{ Leadership Behavior } & $\begin{array}{c}\text { Mean } \\
\text { I describe the kind of future I want my team to create. }\end{array}$ & $\begin{array}{l}\text { Std. } \\
\text { Deviation }\end{array}$ \\
\hline $\mathbf{2}$ & I appeal to others to share my dream of what the future can be like. & 2.62 & 1.11 \\
$\mathbf{3}$ & I communicate clearly a positive and hopeful outlook for the future of the \\
organization. & 3.00 & 1.21 \\
$\mathbf{4}$ & $\begin{array}{l}\text { I show others ho; their long term future interests can be realized by investing in } \\
\text { the common vision }\end{array}$ & 3.05 & 1.29 \\
$\mathbf{5}$ & I look ahead and forecast what I expect the future to be like & 2.70 & 1.14 \\
$\mathbf{6}$ & $\begin{array}{l}\text { I am contagiously excited and enthusiastic about future } \\
\text { Possibilities }\end{array}$ & 2.78 & 1.17 \\
\hline
\end{tabular}

The means for the variables related with "Inspiring a Shared Vision" as indicated in Table 3 above showing others how their long term future interests can be realized by investing in the common vision was ranked the highest practiced with mean score of 3.05. The second ranked statement with the mean score of 3.00 was the extent to which leaders communicate clearly a positive and hopeful outlook for the future of the organization. The lowest ranked variable is describing the kind of future I want my team to create" with the mean score of 2.62. Table 3 also showed that the means of the six variables lies between 2.5 to 3.49 signifying that position holders/leaders/ of different government Offices in Nekemte town inspire a shared vision moderately. The standard deviations results revealed that there is high variation among the respondents on the least ranked variables than the others while there was more agreement regarding explaining the kind of future I want my team to create. It is also interesting to note that the standard deviations for the leadership behaviors 3 and 4 were almost the same.

Moreover, the standard deviation among respondents for variable 1 was slightly higher than that of the highest ranked variables. This indicated that there was less agreement among the respondents regarding the highest ranked variable than the lowest ranked i.e. appealing to share an exciting dream of the future. Generally, the aggregate mean 2.84 shows that the leaders inspire a shared vision moderately.

Table 4: Analysis of the Behaviors of Leaders in enabling others to Act

\begin{tabular}{llll}
\hline & Leadership Behavior & Mean & Std. Deviation \\
\hline $\mathbf{1}$ & I involve the team in planning the action we will be taking. & 3.22 & 1.42 \\
$\mathbf{2}$ & I treat all members of my team with dignity and respect. & 2.98 & 1.31 \\
$\mathbf{3}$ & I give people a lot of discretion to make their own decisions. & 2.63 & 1.17 \\
$\mathbf{4}$ & I develop co-operative relationships with the people I work with & 2.81 & 1.25 \\
$\mathbf{5}$ & I create an atmosphere of mutual trust in the projects I lead & 2.68 & 1.19 \\
$\mathbf{6}$ & I get others to feel a sense of ownership for the projects they & 2.72 & 1.21 \\
& work on & & \\
& Grand Mean & $\mathbf{2 . 8 4}$ & \\
\hline
\end{tabular}

In Table 4, the two highest means for the leadership practice related to "Enabling Others to Act "involve the team in planning the action we will be taking with equal mean score of 3.22. On the other hand, the leadership practice with the least mean score (2.63) was giving people a lot of discretion to make their own decisions. The mean scores for the six behaviors fall between 2.5 to 3.9 signifying that the leaders moderately enable others to act. Moreover, the standard deviations for all the leadership behaviors were high implying that there was high level of variation among the respondents regarding the behaviors exhibited. This may imply that leaders behave differently in different situations so that employees perceive them differently. The analysis of both mean scores and standard deviations revealed that the leadership practice of enabling others to act is moderately exercised by position holders/leaders/ of different government Offices in Nekemte town. Thus, failure to enable and motivate the staff members to act may be an indicator for the leaders' inability to build the capacity of the staffs and reinforce the team spirit needed for extraordinary achievement by organizing on-job training, cheering about key values, making public ceremonies, being personally involved and creating social support rituals (Kouzes \& posner, 2002). In general the extent to which the leaders enable others to act is moderate. 
Table 5: Analysis of Modeling Leadership Behavior

\begin{tabular}{llll}
\hline $\mathbf{2}$ & Leadership Behavior & Mean & Std Deviation \\
\hline $\mathbf{2}$ & I am clear about my own philosophy of leadership. & 2.40 & 1.10 \\
$\mathbf{3}$ & I break projects down into manageable chunks. & 2.65 & 1.18 \\
& $\begin{array}{l}\text { I make sure that people stick with the values that have been } \\
\text { agreed on }\end{array}$ & 3.22 & 1.42 \\
$\mathbf{4}$ & I let others know my beliefs on how to run the team I lead. & 2.56 & 1.14 \\
$\mathbf{5}$ & I am consistent in practicing the values I believe in & 2.80 & 1.24 \\
$\mathbf{6}$ & I make sure that the work group sets clear goals, makes plans \\
& and establishes milestones for the projects I lead & 3.40 & 1.51 \\
& Grand mean & 2.86 &
\end{tabular}

As indicated in Table 5 above making sure that the work group sets clear goals, makes plans and establishes milestones for the projects I lead and make sure that people stick with the values that have been agreed on with mean score ( $3.40 \& 3.22$ respectively) are the highest for Modeling the Way. However, clarity about their own philosophy of leadership is the lowest with mean score of 2.40. In spite of the differences, the means for all behaviors related with "Modeling the Way" fall between 2.5 and 3.49 which indicated that the leaders were moderately engaged in modeling the way. However, It is also interesting to note that the mean for variable 1 was less than 2.5 which indicated that position holders/leaders/ of different government Offices in Nekemte town was below moderate which implies they are unclear about my own philosophy of leadership.

The aggregate mean 2.86 for this dimension shows that position holders/leaders/ of different government Offices are moderately practicing leadership behavior.

Table 6: Analysis of Leaders Behaviors in Encouraging the Heart

\begin{tabular}{|c|c|c|c|}
\hline & Leadership Behavior & Mean & Std. Deviation \\
\hline 1 & I take time to celebrate when project milestones are reached. & 2.75 & 1.21 \\
\hline 2 & $\begin{array}{l}\text { I recognize individuals for their contribution to the success of } \\
\text { the team's work }\end{array}$ & 3.00 & 1.32 \\
\hline 3 & I praise people for a job well done. & 2.6 & 1.14 \\
\hline 4 & $\begin{array}{l}\text { I give team members lots of appreciation and support for their } \\
\text { Contributions }\end{array}$ & 2.87 & 1.26 \\
\hline 5 & I find ways to celebrate team accomplishments & 2.8 & 1.23 \\
\hline 6 & $\begin{array}{l}\text { I make a point of telling the rest of the organization about the } \\
\text { good work of my team }\end{array}$ & 2.94 & 1.29 \\
\hline & Grand mean & 2.83 & \\
\hline
\end{tabular}

Table 6 above indicated that the mean scores for the six variables lies between 2.5 to 3.49 which indicate that position holders/leaders/ of different government Offices in Nekemte town were moderately engaged in encouraging the heart of the workers. The results also showed that recognize individuals for their contribution to the success of the team's work with mean score of 3.00 was the highest ranked while praising and acknowledging staff for a job well done with the mean score 2.60 is least ranked. This may be due to the lack of the culture that values open praises and appreciations, and lack of the awareness on the side of the leaders the motivation power of recognizing others work. Note also that this leadership behavior was the least ranked of the 30 LPI behaviors. Thus, data revealed that position holders/leaders/ of different government Offices in Nekemte town moderately engaged in the practice of Encouraging the heart.

Table 7: Leadership Practices Rank-Ordered

\begin{tabular}{|lll|}
\hline Variables & Mean & Standard Deviation \\
\hline Enabling Others to Act & 17.58 & 7.70 \\
\hline Modeling the Way & 17.04 & 7.55 \\
\hline Inspiring a Shared Vision & 17.03 & 7.59 \\
\hline Encouraging the Heart & 17.01 & 7.19 \\
\hline
\end{tabular}

The rank-ordered leadership practices by means and corresponding standard deviations as indicated in Table 7 showed that the one leadership practice (Challenging the Process) relatively better practiced leadership behavior. The mean for the leadership practice of "Challenging the Process" was 17.758 with the corresponding standard deviation 7.70. The findings of the study generally revealed that position holders/leaders/ of different government Offices in Nekemte town moderately exhibit the five practices of transformational leadership. Kouzes and Posner argue that leaders must demonstrate at least some of the five key 'practices' highly to be successful. The researcher also indicated that specific practices and their characteristics can vary according to different situations, but at some point successful leaders will need to access them all if they have to achieve extraordinary outcome. 


\section{Conclusion and Recommendations \\ Conclusion}

The focus of this study was to assess the practices of exemplary leadership in different government Offices in Nekemte town, Oromia Regional State in light of Kouzes and Posers' leadership practices. As a result of data analysis and the findings of the study, one could conclude that the position holders/leaders/ of different government Offices in Nekemte town moderately Model the Way, Inspire a Shared Vision, Challenge the Process, Enable Others to Act, and Encourage the Heart.

Thus, it could be concluded that since the position holders/leaders/ of different government Offices in Nekemte town did not demonstrate high any of the five key practices it would be possible to conclude that they must be effective as a leaders to improve efficiency, flexibility, effectiveness, accountability, good governance and performance for a organizational success. To prove quality service delivery equally in policy planning, and adequate coordination across public agencies exercising each exemplary leadership practices is mandatory.

\section{Recommendations}

On the basis of Objective of this study and the conclusion drawn from the findings of the study, the researcher would like to offer the following recommendations.

- The first suggestion will be for Oromia Regional State Bureau to plan and invest resources in transformational leadership development of all managers and leadership team members in zonal levels of the region which affects productivity in all angles.

$=$ Secondly, on the basis of this research objective and major findings, the following five models of transformational leadership practices will be suggested for all position holders/leaders/ of different government Offices to implement and become productive leader for Organizational success.

$=$ Challenging the Process; Effective leaders are pioneers; they do not accept the status quo but search out opportunities and step into the unknown. They innovate and experiment and encourage others to do so. They recognize other's good ideas, take risks. They learn by leading in the face of obstacles. Therefore, all leaders on different positions should treat jobs/task as a new adventure, break free of daily routines, devise ways of recognizing and promoting good ideas and foster and encourage people who evaluate then take risks

= Inspiring a Shared Vision; Leaders should be looking to the horizon; imagining the future they want to create. They enlist the emotions of others to share in that vision. They show how mutual commitment to a common purpose is a benefit to all. They suggested to learn from the past, look for gains not losses, Know their followers, Appeal to a common purpose, Communicate expressively and believe in what they are saying

E Enabling Others to Act; Leaders should be stress the team effort, Create interactions, meetings and dialogue, Involve teams in planning and problem solving, Keep people informed, Delegate important work on critical tasks, Allow people to innovate and take risks.

= Modeling the Way; Leaders advised to do what they say they are going to Walk the decks, talk about their beliefs, be expressive, even emotional, about their values, Spend time on the important tasks, Mark out milestones and celebrate achievements and get started, build on successes

= Encouraging the Heart; Leader needs to be Foster high expectations, Be creative in the use of rewards, Say thank you about specific things, Link performance with recognition and reward, Give people feedback about results, Be involved as a cheerleader and Fly the flag for their team.

\section{References}

1. Kouzes, J.M.; Posner, B.Z. The Leadership Challenge: How to Make Extraordinary Things Happen in Organizations, 5th ed.; The Leadership Challenge-A Wiley Brand: San Francisco, CA, USA, 2012.

2. Northouse, P.G. Leadership: Theory and Practice, 7th ed.; SAGE Publications: Thousand Oaks, CA, USA, 2016.

3. Kouzes, J.M.; Posner, B.Z. Development and validation of the Leadership Practices Inventory. Educ. Psychol. Meas. 1988, 48, 483-496.

4. Kouzes, J.M.; Posner, B.Z. Leadership practices: An alternative to the psychological perspective. In Measures of Leadership; Clark, K., Clark, M., Eds.; Leadership Press: Greensboro, NC, USA, 1990.

5. Kouzes, J.M.; Posner, B.Z. Properties of the Leadership Practices Inventory-Updated. Educ. Psych. Meas. 1993, 53, 191-199.

6. $\quad$ Bass, B.M. The Bass Handbook of Leadership, 4th ed.; Simon \& Schuster: New York, NY, USA, 2008.

7. Yukl, G.A. Leadership in Organizations, 8th ed.; Pearson: New York, NY, USA, 2012.

8. Northouse, Peter (2007). Leadership: Theory and Practice (4th edition). Thousand Oaks California: Sage Publications.

9. Bass, B.M.; Riggio, R.E. Transformational Leadership, 2nd ed.; Lawrence Erlbaum Associates, Inc.: 
Mahwah, NJ, USA, 2006.

10. Chen, H.C.; Baron, M. Psychometric properties of the Chinese leadership practices inventory. Int. J. Nurs. Educ. Scholarsh. 2007, 4, 1-13.

11. Carless, S.A.; Wearing, A.J.; Mann, L. A short measure of transformational leadership. J. Bus. Psychol. 2000, 14, 389-405.

12. James M. Kouzes and Posner, Barry Z. 2007. The Leadership Challenge, $4^{\text {th }}$ Edition (San Francisco, CA: Jossey-Bass).

13. Richard C. Roi. 2006. Leadership, Corporate Culture and Financial Performance. Unpublished doctoral dissertation, University of San Francisco.

14. Kouzes, J. \& Posner, B. (2008). The Student Leadership Challenge: Five practices for exemplary leaders. San Francisco, CA: Josey-Bass.

15. Kouze, JM and Posner, BZ (1995) The Leadership Chaflenge Jossey-Bass, San Francisco

16. Tampoe, M (1998) Liberating Leadership Industrial Society, London

17. Boehnke, K., Bontis, N. Distefano, J., \& Distefano, A. (2003). Transformational Leadership:

18. D. Quinn Mills,(2005). Leadership, How to lead How to live. http://www.cafanet.com/

19. Yukl, Gary (2002). Leadership in Organizations. Englewood, New Jersey: Prentice Hall.

20. Dubrin, A. J. (2001). Leadership research finding, practices, and skills. (3rd ed). Boston, New York: Houghton Mifflin Company.

21. Judge, T. A., Bono, J.E., Ilies, R. and Gerhardt, M.W. (2002). Personality \& leadership: A Qualitative \& Quantitative Review. Journal of Applied Psychology, 87(4): 765-780.

22. Judge, T. A. \& Piccolo, R. F. (2004). Transformational \& Transactional Leadership: A Meta-analytic Test of their Relative Validity. Journal of Applied Psychology, 89(5): 755-768.

23. Zhu, W., Chew, I. K. h. \& Spangler, W. D. (2005). CEO Transformational Leadership \& Organizational Outcomes: The Mediating Role of Human-Capital-Enhancing Human Resource Management. The Leadership Quarterly, 16(1): 39-52.

24. OECD, (2011). Public sector leadership for the 21st century: executive summary. Paris.36.65-74

25. Owen, S. (2011). Leadership Traits That Most Impact Success. Right management.

26. Ramnarayan, S. \& Kumar, K. (2004). Strengthening Leadership in Government Organizations. Public Sector Leadership for the 21 st Century. 